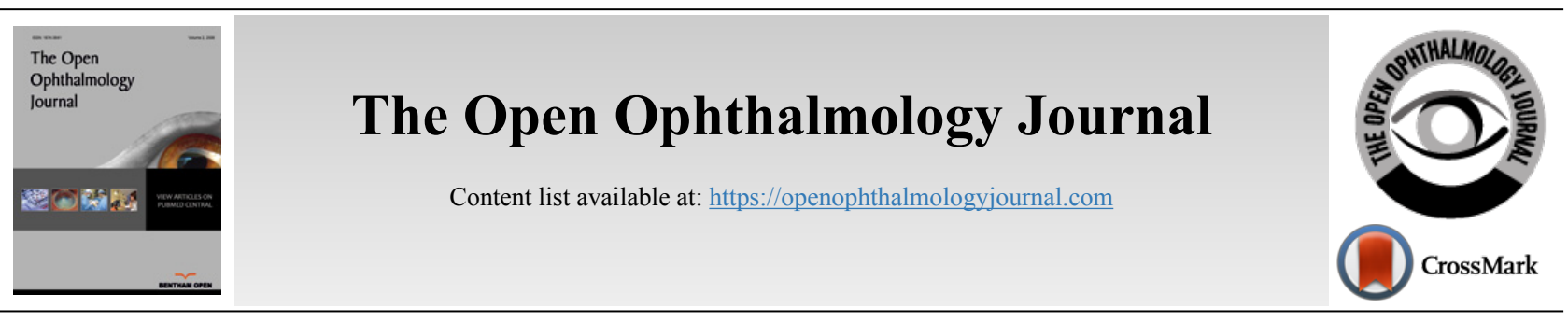

CASE REPORT

\title{
Multi-modal Imaging in Etanercept-induced Uveitis: A Case Series
}

\author{
Jaidip Gill $^{1, *}$, Robert Barry ${ }^{1}$, Shreekanth Sreekantam ${ }^{1}$ and Bashar Mohammed ${ }^{1}$ \\ ${ }^{I}$ Birmingham and Midlands Eye Centre, Sandwell and West Birmingham NHS Trust, Birmingham, United Kingdom
}

\begin{abstract}
:
Introduction:

To report with multi-modal imaging the clinical course of 3 patients with new-onset uveitis following treatment with etanercept.

Methods:

Retrospective case-note reviews were conducted of 3 patients previously established on etanercept who developed new-onset acute uveitis.

Results and Discussion:

Three patients were assessed with a mean age of 44.3 (43-47). Etanercept was indicated for the treatment of ankylosing spondylitis in two patients and psoriatic arthritis in 1 patient. Duration of etanercept treatment ranged from 7 to 10 years; however, in two cases, treatment recently changed to an etanercept biosimilar agent. Two patients were diagnosed with bilateral panuveitis and one patient had chronic relapsing anterior uveitis. Infection screen was negative in all three patients. 2 patients developed cystoid macular oedema as viewed on Spectral Domain OCT. Fundus fluorescein angiography was performed in one patient who demonstrated bilateral retinal vasculitis. All three patients were started on systemic and topical treatment. One patient received sub-tenon triamcinolone injection. Etanercept was discontinued for all patients. 1 of 3 patients lost vision at 7 months. 2 patients demonstrated long-term remission and one patient required intravitreal steroid implantation to stabilize an ongoing intraocular inflammation. Two patients who had complete remission were commenced on Adalimumab while the third patient was commenced on Secukinumab.

\section{Conclusion:}

The clinical course of uveitis developing paradoxically following etanercept treatment is variable. Multi-modal imaging is useful for the clinician that helps in diagnosing and monitoring associated macular oedema and retinal ischaemia. Cessation of etanercept and systemic corticosteroid treatment are often required to prevent ocular morbidity.
\end{abstract}

Keywords: Etanercept, Uveitis, Paradoxical adverse effects, Multi-modal imaging, Ocular inflammation, Ocular morbidity.

\begin{tabular}{l|l|l|r} 
Article History & Received: April 27, 2020 & Revised: August 24, 2020 & Accepted: September 30, 2020
\end{tabular}

\section{INTRODUCTION}

Of the Anti-tumour Necrosis Factor (TNF) agents available for the treatment of rheumatological conditions, etanercept is most likely to be associated with the paradoxical instigation of uveitis in previously unaffected patients [1 - 3]. Early reports of this interesting phenomenon cited anecdotal evidence of the temporal relationship of resolution after drug discontinuation and positive rechallenge tests to implicate etanercept [4 - 6]. Large registry-based studies and systematic reviews argued not only that etanercept was less effective than other anti-TNF agents in reducing uveitis flares but also more likely to cause

\footnotetext{
* Address correspondence to this author at the Birmingham and Midlands Eye Centre, Sandwell and West Birmingham NHS Trust, Dudley Road, Birmingham, B18 7QH, United Kingdom; Tel: 07960220702; E-mail: jaigil@gmail.com
}

new-onset uveitis compared to other anti-TNF agents [3, 7 $10]$.

The precise pathogenesis of these so-called Paradoxical Adverse Effects (PAE) is unclear, however, an imbalance in the cytokine milieu induced by TNF blockade has been hypothesized as the most likely mechanism. Other authors have suggested that TNF-alpha blockade increases susceptibility to infection from non-tuberculous Mycobacterium species and Propionibacterium acnes, which results in non-caseating granuloma formation [11]. Further, the differential immunological properties of the TNF-a soluble receptor of etanercept compared to the monoclonal antibodies have been postulated to explain the predilection of ocular inflammation in the former [12]. 
Table 1. Patient characteristics and demographic data.

\begin{tabular}{|c|c|c|c|c|c|c|c|c|c|c|}
\hline Patient & Age & $\begin{array}{c}\text { Systemic } \\
\text { Disease }\end{array}$ & $\begin{array}{c}\text { Ocular } \\
\text { Involvement }\end{array}$ & $\begin{array}{c}\text { Interval of } \\
\text { Etanercept } \\
\text { Treatment } \\
\text { to Onset of } \\
\text { Uveitis }\end{array}$ & $\begin{array}{c}\text { Corticosteroid } \\
\text { Treatment }\end{array}$ & $\begin{array}{c}\text { Modification to } \\
\text { Biologic } \\
\text { Treatment }\end{array}$ & \begin{tabular}{|c|} 
VA on \\
Presentation
\end{tabular} & $\begin{array}{c}\text { Follow-up } \\
\text { Duration } \\
\text { (months) }\end{array}$ & \begin{tabular}{|c|} 
VA at \\
Last \\
Follow \\
up
\end{tabular} & Outcome \\
\hline 1 & $43(\mathrm{~F})$ & PA & $\begin{array}{c}\text { Bilateral } \\
\text { panuveitis }+ \\
\text { Macular oedema }\end{array}$ & - & $\begin{array}{c}\text { Topical + pulsed } \\
\text { IVMP + oral }\end{array}$ & $\begin{array}{l}\text { Switched to } \\
\text { Adalimumab }\end{array}$ & $\begin{array}{l}\text { RE: } 6 / 36 \\
\text { LE: } 6 / 18\end{array}$ & 21 & $6 / 6$ & Remission \\
\hline 2 & $43(\mathrm{M})$ & AS & $\begin{array}{c}\text { Bilateral pan } \\
\text { uveitis + retinal } \\
\text { vasculitis }\end{array}$ & - & Topical + Oral & $\begin{array}{l}\text { Switched to } \\
\text { adalimumab }\end{array}$ & $\begin{array}{l}\text { RE: } 6 / 6 \\
\text { LE: } 6 / 6\end{array}$ & 24 & $6 / 6$ & Remission \\
\hline 3 & $47(\mathrm{M})$ & AS & $\begin{array}{c}\text { Left AAU + } \\
\text { Macular oedema }\end{array}$ & - & $\begin{array}{c}\text { Topical + sub- } \\
\text { tenon }+ \text { oral }+ \\
\text { intravitreal }\end{array}$ & \begin{tabular}{|c|} 
Switched to \\
Certolizumab pegol \\
(ineffective); re- \\
challenge of \\
etanercept \\
(exacerbation); \\
switched to \\
Secukinumab \\
(incomplete \\
remission)
\end{tabular} & LE: $6 / 6$ & 7 & $6 / 12$ & $\begin{array}{c}\text { Partial } \\
\text { remission } \\
\text { requiring } \\
\text { ongoing } \\
\text { treatment }\end{array}$ \\
\hline
\end{tabular}

F, Female; M, Male; PA, Psoriatic arthritis; AS, Ankylosing Spondylitis; AAU, Acute Anterior Uveitis; RE, Right Eye; LE, Left Eye; VA, Visual Acuity.

To date, the clinical parameters of patients with etanerceptinduced uveitis have been elucidated only briefly in large retrospective studies or described in case reviews with limited imaging data. Our aim is to report the presentation, clinical course and management of 3 patients with etanercept-induced uveitis. We additionally evaluate the utility of multi-modal imaging techniques in the assessment, treatment and monitoring of these patients.

\section{CASE REPORT}

Three patients established on etanercept treatment who developed uveitis were identified (Table 1). All three patients denied previous episodes of uveitis.

\subsection{Case 1}

A 43-years-old Caucasian female was referred by her optician to the emergency department complaining of bilateral red and photophobic eyes for 1 week. She had a medical history of psoriatic arthritis and had been taking Etanercept (Enbrel, Pfizer, Brussels, Belgium) for 10 years. Her visual acuities were $6 / 36$ in the right eye and 6/18 in the left eye (Snellen chart). Slit-lamp biomicroscopy was significant for injected conjunctivae and granulomatous "mutton fat" keratic precipitates were seen on the corneal endothelium. Anterior chamber (AC) cell activity was graded as $0.5+$ in the right eye and $1+$ in the left eye according to the SUN (standardisation of uveitis nomenclature) working group classification [13]. Her intraocular pressures were within normal limits and she did not have any evidence of intermediate or posterior uveitis.

She initially received treatment with intensive topical corticosteroids. At 1 week, her visual acuities remained unchanged with an increase in AC cell activity (2+ in the right eye and $1+$ in the left eye). Optical Coherence Tomography (OCT) scans demonstrated gross macular oedema affecting both eyes (Fig. 1).

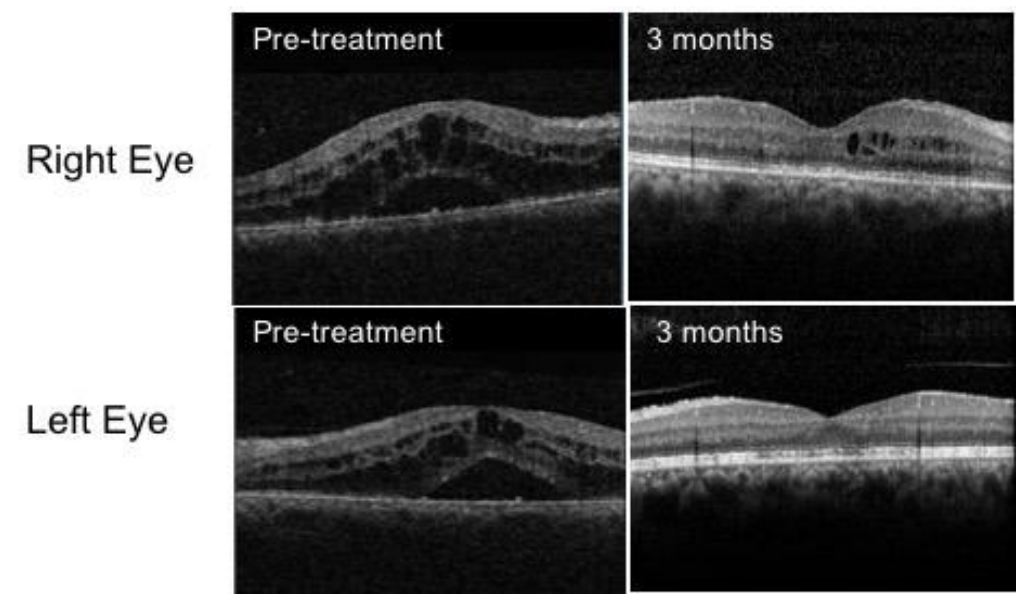

Fig. (1). OCT images of Case 1 at pre-treatment and at 3 months. Pre-treatment images show gross Cystoid Macula Oedema (CMO) in both eyes with intra-retinal cysts and subretinal fluid. Improvement is seen at 3 months, corresponding to an improvement in visual acuity. 


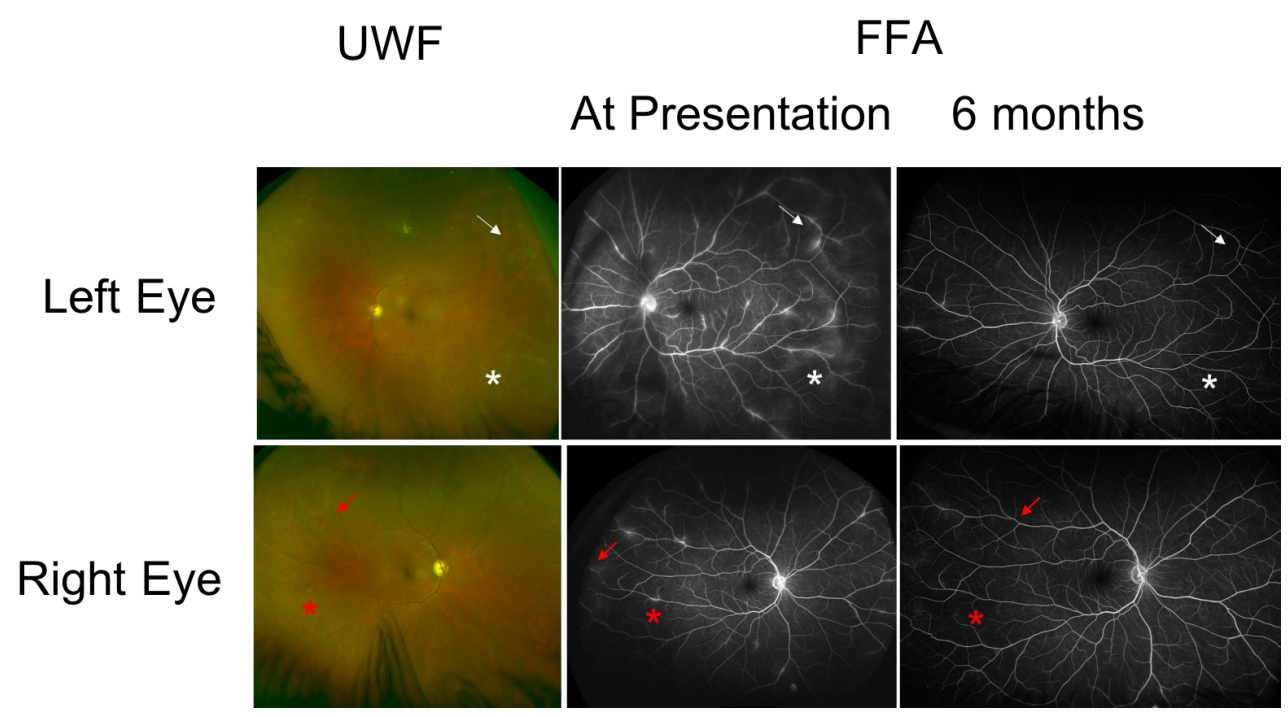

Fig. (2). Case 2: Ultra-Wide Field (UWF) pseudo colour fundus photograph at presentation (OPTOS, California) and late phase wide field fundus fluorescein angiography at presentation and 6 months following treatment. Arrows and stars show corresponding areas of peripheral retinal vasculitis and sheathing of retinal vessels. FFA shows late leakage of fluorescein which resolved at 6 months. The lesions are asymmetric with the left eye more affected. Vitreous haze indicative of vitritis is seen in both UWF pictures.

Oral prednisolone was commenced at a dose of $30 \mathrm{mg} /$ day. A baseline uveitis screening blood panel including serum ACE, blood-borne viruses, treponemal serology and T-spot with a chest $\mathrm{X}$-ray was ordered to rule out infectious aetiologies and other pathologies, such as sarcoidosis, all were normal.

At 4 weeks, she reported no improvement in her vision and the macular oedema was persistent, necessitating 3 pulsed doses of intravenous methylprednisolone at a dose of $1 \mathrm{mg} / \mathrm{kg}$ followed by a tapering course of oral prednisolone. She was referred to the rheumatologist who had recommended discontinuing etanercept treatment.

Her vision improved over the next six weeks with quiescent eyes and resolution of macular oedema (Fig. 1). Her treatment has been changed to adalimumab at 3 months and she maintained good BCVA at $6 / 9$ in the right eye and $6 / 6$ in the left at 21 months of follow-up.

\subsection{Case 2}

A 43-years-old male with a background of Ankylosing Spondylitis (AS) treated with etanercept for 9 years presented to the Eye Casualty service with a one-week history of painful, red left eye with visual blurring. One month prior to his presentation, his rheumatologist switched his etanercept from Enbrel to a biosimilar agent Benepali (Samsung Bioepis, Delft, the Netherlands). His visual acuities were $6 / 6$ in both eyes. Slitlamp biomicroscopy of the left eye showed fine small keratic precipitates on the corneal endothelium and $2+$ cells in the AC with 1+ flare. Intraocular pressures were within normal limits. Dilated fundal examination showed active vitritis with vitreous condensation (snowballs) in both eyes. He had bilateral but asymmetrical retinal peri-phlebitis with venous sheathing (Fig. 2).

A full uveitis blood screen including tuberculosis QuantiFERON, ANCA, ACE and treponemal serology was negative. An anterior chamber paracentesis was performed, which was negative for atypical cells, TB fungal or bacterial nucleic acid. Polymerase chain reaction testing of cytomegalovirus, Herpes simplex virus, varicella zoster virus was negative as well as serology for Bartonela, Borrelia and Treponema Pallidum. OCT showed no evidence of macula oedema. FFA confirmed the presence of active retinal vasculitis and leakage from retinal vessels in both eyes, with the left more florid than the right (Fig. 2).

He was treated with tapering oral prednisolone (starting at $40 \mathrm{mg}$ OD for a week) along with topical corticosteroids and a recommendation was made to the rheumatologist to consider an alternative agent to etanercept. Vision remained at $6 / 6$ in both eyes at 6 months (Fig. 2) but a repeat FFA showed improvement in the leakage around blood vessels. His rheumatologist switched his treatment to Adalimumab. At 24 months of follow-up, he had some very small areas of perivascular sheathing in both eyes with longstanding vitreous snowballs but maintained good vision at $6 / 6$ in both eyes.

\subsection{Case 3}

A 47-years-old Caucasian male with a history of Ankylosing Spondylitis treated with etanercept for 7 years presented to the Eye Casualty department with a 1-week history of cloudy vision, pain, redness and photophobia in the left eye. Two months prior to his presentation, his rheumatologist switched his etanercept treatment from Enbrel to a biosimilar agent Erelzi (Sandoz, Kundl, Austria).

His Snellen visual acuity was $6 / 6$ in both eyes on presentation. Biomicroscopy examination demonstrated small keratic precipitates in the left eye with $3+$ of cells in the AC. He did not have any vitiritis or posterior uveitis. Macula and optic disc appearances were normal.

His symptoms improved with a slow tapering course of topical corticosteroids and he was discharged at 7 weeks following complete resolution of the anterior uveitis. However, 
at 11 weeks, he re-presented with similar symptoms and was found to have recurrent acute anterior uveitis in the same eye with a reduction in BCVA to 6/24. An infectious blood screening panel was ordered along with Serum ACE and a chest x-ray which were all within normal limits. OCT scanning showed gross macular oedema which did not respond to subtenon triamcinolone injections. He was treated at this stage with $40 \mathrm{mg}$ oral prednisolone on a tapering basis.

His biologic treatment was altered multiple times, including trials of Certolizumab pegol and a re-challenge with etanercept. These were ineffective in controlling his ocular inflammation with etanercept, actually causing a flare-up of uveitis once again. Adalimumab was not used as previously as it was not effective in controlling his joint disease. Finally, he was started on Secukinumab, a monoclonal antibody that inhibits the cytokine interleukin 17A. At 7 months, he was found to have persistent low-grade anterior uveitis and CMO. Following a discussion of the risks and benefits, he was scheduled for an intravitreal dexamethasone implant injection (Ozurdex, Allergan Ltd., UK). BCVA in the left eye was 6/12 at 7 months of follow up.

\section{DISCUSSION}

In this case series, we describe multi-modal imaging on 3 patients who developed new-onset uveitis having been established on etanercept for systemic immune-mediated conditions. All 3 patients had no history of ocular inflammation and presented with a fairly acute onset of uveitis. Our patients demonstrated variable clinical characteristics of ocular inflammation, including panuvetis, retinal vasculitis, vitrifies and relapsing AAU. The time range of starting etanercept to developing PAEs has been described in other studies as the variable.

Our study showed a time of uveitis onset ranging from 7 to 10 years of established etanercept treatment which is consistent with the variability reported by other studies [1,3]. Of note, 2 patients recently had their treatment changed to biosimilar agents within 2 months of presentation. Biosimilar agents are now more commonly being prescribed for cost-saving measures. The equivalence studies for both new agents did not identify any significant increase in the incidence of ocular inflammation [14]. Additionally, abstract data for Erelzi and real-world data for Benepali studies showed no new safety signals compared to reference agents $[15,16]$. Furthermore, switching to anti-TNF alpha biosimilars used to treat uveitis specifically demonstrated no statistically significant difference in the rate of uveitis flares [17].

Multi-modal imaging was useful to document and monitor intraocular inflammation. In particular, OCT imaging can be used to target treatment towards CMO. Fluorescein angiography is useful to assess the extent of vessel leakage, retinal ischaemia and to identify the involvement of the fellow eye if this is not already clear. Ultrawidefield imaging, now readily available in ophthalmology departments, is also useful to examine and document lesions of the peripheral retina. It is clear that the presentation of such cases can be varied; however, the clinician must keep a high index of suspicion and ensure that infection has been ruled out first.
The patients we presented had variable success with topical treatment alone. All three patients ultimately required systemic corticosteroids. Interestingly a trial of sub-tenon triamcinolone alone was not seen to be effective to resolve the case with CMO.

We found it useful to liaise with the rheumatologists to help with switching to a new agent, especially considering these patients had no previous ocular involvement of their underlying rheumatological disease. Etanercept was eventually discontinued for all patients (Table 1). Remission was achieved when treatment was switched to adalimumab in 2 out of 3 patients; however, switching to certolizumab pegol was not as successful. One patient had another positive re-challenge test when etanercept (Enbrel) was introduced.

The fact that 2 out of our 3 patients had their uveitis initiated within months of switching to a biosimilar agent raises some suspicion of some instigating mechanism in this switch. However, safety data obtained from larger and randomised studies does not support this observation [18 - 20].

\section{CONCLUSION}

At the onset of vision-threatening uveitis, the authors support the initiation of systemic corticosteroids once an infective cause has been excluded. Our cases demonstrated favourable outcomes once etanercept was discontinued, and a different anti-TNF agent was initiated. We also support the use of multiple ophthalmic imaging modalities to assess, monitor and document the progress of these patients. The temporal correlation of switching to biosimilar anti-TNF agents and the onset of uveitis in our patients raise the possibility of an instigating mechanism, although further investigation will be required.

\section{ETHICS APPROVAL AND CONSENT TO PARTICIPATE}

Not applicable.

\section{HUMAN AND ANIMAL RIGHTS}

Not applicable.

\section{CONSENT FOR PUBLICATION}

Informed consent was taken from all patients when they were enrolled.

\section{STANDARDS OF REPORTING}

This article was written in accordance with CARE guidelines and methodologies.

\section{FUNDING}

None.

\section{CONFLICT OF INTEREST}

The authors report no conflicts of interest. The authors alone are responsible for the content and writing of this paper. 


\section{ACKNOWLEDGEMENTS}

Declared none.

\section{REFERENCES}

[1] Lim LL, Fraunfelder FW, Rosenbaum JT. Do tumor necrosis factor inhibitors cause uveitis? A registry-based study. Arthritis Rheum 2007; 56(10): 3248-52.

[http://dx.doi.org/10.1002/art.22918] [PMID: 17907169]

[2] Kakkassery V, Mergler S, Pleyer U. Anti-TNF- $\alpha$ treatment: A possible promoter in endogenous uveitis? observational report on six patients: Occurrence of uveitis following etanercept treatment. Curr Eye Res 2010; 35(8): 751-6.

[http://dx.doi.org/10.3109/02713683.2010.486520] [PMID: 20673052]

[3] Wendling D, Paccou J, Berthelot J-M, et al. New onset of uveitis during anti-tumor necrosis factor treatment for rheumatic diseases. Semin Arthritis Rheum 2011; 41(3): 503-10.

[http://dx.doi.org/10.1016/j.semarthrit.2011.05.005] [PMID: 21862108]

[4] Reddy AR, Backhouse OC. Does etanercept induce uveitis? Br J Ophthalmol 2003; 87(7): 925.

[http://dx.doi.org/10.1136/bjo.87.7.925] [PMID: 12812909]

[5] Taban M, Dupps WJ, Mandell B, Perez VL. Etanercept (enbrel)associated inflammatory eye disease: Case report and review of the literature. Ocul Immunol Inflamm 2006; 14(3): 145-50. [http://dx.doi.org/10.1080/09273940600659393] [PMID: 16766397]

[6] Coates LC, McGonagle DG, Bennett AN, Emery P, Marzo-Ortega H. Uveitis and tumour necrosis factor blockade in ankylosing spondylitis. Ann Rheum Dis 2008; 67(5): 729-30.

[http://dx.doi.org/10.1136/ard.2007.077370] [PMID: 18408116]

[7] Heiligenhaus A, Michels H, Schumacher C, et al. Evidence-based, interdisciplinary guidelines for anti-inflammatory treatment of uveitis associated with juvenile idiopathic arthritis. Rheumatol Int 2012; 32(5): 1121-33

[http://dx.doi.org/10.1007/s00296-011-2126-1] [PMID: 22083610]

[8] Levy-Clarke G, Jabs DA, Read RW, Rosenbaum JT, Vitale A, Van Gelder RN. Expert panel recommendations for the use of anti-tumor necrosis factor biologic agents in patients with ocular inflammatory disorders. Ophthalmology 2014; 121(3): 785-96.e3.

[http://dx.doi.org/10.1016/j.ophtha.2013.09.048] [PMID: 24359625]

[9] Cobo-Ibáñez T, del Carmen Ordóñez M, Muñoz-Fernández S, Madero-Prado R, Martín-Mola E. Do TNF-blockers reduce or induce uveitis? Rheumatology (Oxford) 2008; 47(5): 731-2. [http://dx.doi.org/10.1093/rheumatology/ken091] [PMID: 18346974]

[10] Galor A, Perez VL, Hammel JP, Lowder CY. Differential effectiveness of etanercept and infliximab in the treatment of ocular inflammation. Ophthalmology 2006; 113(12): 2317-23. [http://dx.doi.org/10.1016/j.ophtha.2006.04.038] [PMID: 16996615]
[11] Daïen CI, Monnier A, Claudepierre P, et al. Sarcoid-like granulomatosis in patients treated with tumor necrosis factor blockers: 10 cases. Rheumatology (Oxford) 2009; 48(8): 883-6. [http://dx.doi.org/10.1093/rheumatology/kep046] [PMID: 19423648]

[12] Toussirot É, Aubin F. Paradoxical reactions under TNF- $\alpha$ blocking agents and other biological agents given for chronic immune-mediated diseases: An analytical and comprehensive overview. RMD Open 2016; 2(2)e000239

[http://dx.doi.org/10.1136/rmdopen-2015-000239] [PMID: 27493788]

[13] Jabs DA, Nussenblatt RB, Rosenbaum JT. Standardization of uveitis nomenclature for reporting clinical data. Results of the first international workshop. Am J Ophthalmol 2005; 140(3): 509-16. [http://dx.doi.org/10.1016/j.ajo.2005.03.057] [PMID: 16196117]

[14] Chadwick L, Zhao S, Mysler E, Moots RJ. Review of biosimilar trials and data on etanercept in rheumatoid arthritis. Curr Rheumatol Rep 2018; 20(12): 84 .

[http://dx.doi.org/10.1007/s11926-018-0799-0] [PMID: 30411183]

[15] Ebbers HC, Pieper B, Issa A, Addison J, Freudensprung U, Rezk MF. Real-world evidence on etanercept biosimilar sb4 in etanercept-naïve or switching patients: A systematic review. Rheumatol Ther 2019; 6(3): $317-38$

[http://dx.doi.org/10.1007/s40744-019-00169-4] [PMID: 31385263]

[16] Schmalzing M, Askari A, Walsh D, et al. Etanercept biosimilar GP 2015 ( Erelzi ) in rheumatic diseases : Interim analysis of real-world data from compact : A multicentric, prospective, observational cohort study. 2019.

[17] Fabiani C, Vitale A, Emmi G, et al. The role of biosimilars in uveitis: Long-term real-world outcomes of the switch from original to biosimilar TNF-alpha inhibitors. Front Pharmacol 2019; 10: 1468. [http://dx.doi.org/10.3389/fphar.2019.01468] [PMID: 31920658]

[18] Emery P, Vencovský J, Sylwestrzak A, et al. Long-term efficacy and safety in patients with rheumatoid arthritis continuing on SB4 or switching from reference etanercept to SB4. Ann Rheum Dis 2017; 76: 1986-91.

[http://dx.doi.org/10.1136/annrheumdis-2017-211591]

[PMID: 28794078]

[19] Emery P, Vencovský J, Sylwestrzak A, et al. A phase III randomised, double-blind, parallel-group study comparing SB4 with etanercept reference product in patients with active rheumatoid arthritis despite methotrexate therapy. Ann Rheum Dis 2017; 76(1): 51-7. [http://dx.doi.org/10.1136/annrheumdis-2015-207588] 26150601]

[20] Jaworski J, Matucci-Cerinic M, Schulze-Koops H, et al. Switch from reference etanercept to SDZ ETN, an etanercept biosimilar, does not impact efficacy, safety, and immunogenicity of etanercept in patients with moderate-to-severe rheumatoid arthritis: 48-week results from the phase III, randomized, double-blind EQUIRA study. Arthritis Res Ther $2019 ; 21(1): 130$.

[http://dx.doi.org/10.1186/s13075-019-1907-x] [PMID: 31138316]

\section{(C) 2020 Gill et al.}

This is an open access article distributed under the terms of the Creative Commons Attribution 4.0 International Public License (CC-BY 4.0), a copy of which is available at: (https://creativecommons.org/licenses/by/4.0/legalcode). This license permits unrestricted use, distribution, and reproduction in any medium, provided the original author and source are credited. 